\title{
Synthesis and Characterization of $\mathrm{Zr}$ Doped $\mathrm{BaCeO}_{3}$ by Citrate-EDTA Complexing Sol-Gel Process for Solid Oxide Fuel Cell
}

\author{
J. MADHURI SAILAJA, K. VIJAYA BABU, \\ N. MURALI, K. SAMATHA and V. VEERAIAH
}

Department of Physics, Andhra University, Vishakhapatnam, Andhra Pradesh, India

madhurisailaja1981@gmail.com

Received 13 May 2016 / Accepted 3 June 2016

\begin{abstract}
Polycrystalline $\mathrm{BaCeO}_{3}$ and $\mathrm{BaCe}_{0.7} \mathrm{Zr}_{0.3} \mathrm{O}_{3}$ were prepared by using the citrate-EDTA complexing sol-gel process at low temperature $\left(\mathrm{T}=1000{ }^{\circ} \mathrm{C}\right)$. The pure phase formation with temperature was studied by $\mathrm{x}$-ray diffraction (XRD) and thermal analysis (TG-DTA). The crystallite size of the ceramic powders was calculated from Scherrer's equation. A slight decrease in the crystallite size was found when $\mathrm{Zr}$ was doped and the diffraction peak shifted to higher angles. Morphology of the powders sintered at $\mathrm{T}=1300{ }^{\circ} \mathrm{C}$ exhibited a slight decrease in the average grain size from $1.33 \mu \mathrm{m}$ to $1.25 \mu \mathrm{m}$. This is consistent with the fact that the grain size decreased as the ionic radius of $\mathrm{Zr}$ is less than $\mathrm{Ce}$. Dense ceramic materials were obtained at $\mathrm{T}=1300{ }^{\circ} \mathrm{C}$ and the relative density were found to be $79 \%$ of the theoretical density. FTIR and Raman measurements revealed the complete single phase formation of the perovskite. The ionic conductivities of both the compounds were investigated from $30-400{ }^{\circ} \mathrm{C}$ and are found to be $1.92 \times 10^{-6} \mathrm{~S} \mathrm{~cm}^{-1}$ and $1.35 \times 10^{-6} \mathrm{~S} \mathrm{~cm}^{-1}$ at $400{ }^{\circ} \mathrm{C}$ respectively. The conductivity decreases as temperature increases and the activation energies are $1.21 \mathrm{eV}$ and $1.34 \mathrm{eV}$ respectively. These values are in agreement with that available in the literature.
\end{abstract}

Keywords: $\mathrm{BaCeO}_{3}$, Citrate-EDTA complexing sol-gel process, Perovskite, Fuel cells, Protonic conductor

\section{Introduction}

Increasing greenhouse gas (GHG) emissions worldwide have resulted in an increased interest in the development in alternative technologies such as fuel cells. Fuel cells are very promising in the transportation and stationary power generation sectors ${ }^{1-4}$. A new type of solid oxide fuel cells (SOFCs) based on ceramic electrolyte materials that exhibit high protonic conductivity at temperatures in the range of $400-600{ }^{\circ} \mathrm{C}$, is being developed: the protonic ceramic fuel cells (PCFC). The PCFC performances are mostly calculated by the 
bulk conductivity of the electrolyte at the temperatures at which these devices typically operate. Then, it is essential to understand electrolyte properties of the bulk material if high performance fuel cells are to be designed. A large number of perovskite-type ceramic materials with high protonic conductivity have been identified and synthesised. Among them are the perovskite crystals such as $\mathrm{BaZrO}_{3}$ and $\mathrm{BaCeO}_{3}$. Materials based on $\mathrm{BaCeO}_{3}$ are known not only for their proton conductivity in hydrogen and/or steam atmospheres at high temperatures, but also because they have higher hydrogen solubility than other metal oxides. They are considered to be possible sensors for hydrogen or humidity and new materials for hydrogen storage. Furthermore, these oxides have shown easy hydrogen charge/ discharge performance at room temperature and are considered to be potential material in hydrogen storage alloys in the nickel-hydrogen batteries. But the key issue is the synthesis of a highly proton conductive electrolyte with enhanced chemical stability. $\mathrm{BaCeO}_{3}$ and $\mathrm{BaZrO}_{3}$ can easily form a solid solution across the entire composition range and it has been demonstrated viable to replace a portion of $\mathrm{Ce}$ with $\mathrm{Zr}$ which increased chemical stability ${ }^{5-8}$.

Conventionally, the ceramic electrolytes have been prepared by solid-state reaction (SSR) method which employed ball-milled, repetitive grinding and high-temperature treatment $\left(\mathrm{T}=1400{ }^{\circ} \mathrm{C}\right)$. As a consequence, some impurities and contaminations were introduced through the heat treatment process which cause sample degradation. To overcome the SSR shortcomings, wet chemical methods (WCMs) such as sol-gel, hydrothermal, co-precipitation, etc., ${ }^{5,6,9}$ is adopted to obtain the desired perovskite compound. With the help of these methods fine powder morphologies with less contamination are obtained. Sol-gel and Pechini method utilizes the ability of citric acid and ethylenediaminetetra acetic acid (EDTA) to form polybasic acid chelated with several metal cations $^{10,11}$. As a result, the methods are able to produce a single-phase powder and dense pellet at relatively low temperature $\left(800-1400{ }^{\circ} \mathrm{C}\right)$. The reduction in processing temperature may due to the sol-gel process assisted with a complexing or chelating agents. The agents are able to homogenize and mix raw materials at molecular level which may enhance the reaction rate and decrease the processing temperature. Details elucidation of thermal degradation characteristic of chelating agents with metal cations were reported by various researchers ${ }^{12-14}$ had also discussed the role of chelating agents in reducing the processing temperature to produce nanocrystalline sample. Furthermore, the effect of various single and combined chelating agents on the crystalline phase and grain size as well as particle size of ceramics sample was reported.

\section{Experimental}

The citrate-EDTA complexing sol-gel process was used for preparing $\mathrm{BaCeO}_{3}$ and $\mathrm{BaCe}_{0.7} \mathrm{Zr}_{0.3} \mathrm{O}_{3}$ oxides. The starting materials were commercial $\mathrm{Ba}\left(\mathrm{NO}_{3}\right)_{2}, \mathrm{ZrO}$ $\left(\mathrm{NO}_{3}\right)_{2} \cdot 2 \mathrm{H}_{2} \mathrm{O}, \mathrm{Ce}\left(\mathrm{NO}_{3}\right)_{3} 6 \mathrm{H}_{2} \mathrm{O}$ (High Media, 99.5\%). Both citric acid and EDTA were used as chelating agents to the precursor solution. The molar ratio of citric acid and EDTA to the total metal cations content was set at 1:2:1. The $\mathrm{pH}$ value of the solution was adjusted to be around 6 using $\mathrm{NH}_{4} \mathrm{OH}$. The mixed solutions were heated to $100{ }^{\circ} \mathrm{C}$ under stirring until viscous gels were obtained. When further heated at $250{ }^{\circ} \mathrm{C}$ to evaporate residual water and organics, these gels were converted into black powders. The synthesized powders were then calcined at $1000{ }^{\circ} \mathrm{C}$ for $12 \mathrm{~h}$ with a heating rate of $5{ }^{\circ} \mathrm{C} / \mathrm{min}$. To obtain dense samples, the calcined powders were uniaxially pressed into cylindrical pellets $(1 \mathrm{~cm}$ in diameter and $1 \mathrm{~mm}$ in thickness) at 5 ton for $5 \mathrm{~min}$ and then sintered in an air atmosphere. Sintering was carried out at $1300{ }^{\circ} \mathrm{C}$ for $5 \mathrm{~h}$ at a heating rate of $5{ }^{\circ} \mathrm{C} / \mathrm{min}$. 


\section{Characterization}

Thermogravimetric analysis (TGA) have been carried out to the dried powder $\left(\mathrm{T}=250{ }^{\circ} \mathrm{C}\right)$ by a TGA instrument model (SDT Q 600). The phase identification of the sintered oxides was performed with a powder diffractometer (PANalytical X-pert Pro) with $\mathrm{Ni}$ filtered $\mathrm{Cu}$ $\mathrm{K} \alpha$ radiation and the diffraction angle from $10^{\circ}$ to $90^{\circ}$ with a step of $0.01 / \mathrm{min}$. Morphologies of the sintered pellets were examined using Scanning Electron Microscope (JEOL JSM-6610 LV) in conjunction with an energy dispersion spectrometer (EDS) find out the percentage of elements present in the samples. A FTIR spectrometer (SHIMADZU IR Prestige-21, Singapore) was employed to record the spectra of synthesized powders in the range of 4000 to $400 \mathrm{~cm}^{-1}$ to investigate the complex, carbonates and oxides formation. The theoretical density of the powders was calculated with the obtained XRD. Fourier Transform Raman spectroscopy (BTC111-RAMAN-785) studies were conducted to study the vibrational modes of the samples in the range $0-1000 \mathrm{~cm}^{-1}$ LCR measurements from room temperature to $400{ }^{\circ} \mathrm{C}$ were performed with Wayne-kerr P6500 model in the frequency range from $20 \mathrm{~Hz}$ to $1 \mathrm{MHz}$.

\section{Results and Discussion}

\section{Thermogravimetry/differential thermal analysis}

To investigate the reaction during the formation of the perovskite phase structure, simultaneous TG-DTA curves of the sample conducted from room temperature to $1200{ }^{\circ} \mathrm{C}$ was presented in Figure 1. In terms of thermal stability nitrates are unstable than carbonate and hence are decomposed easily.

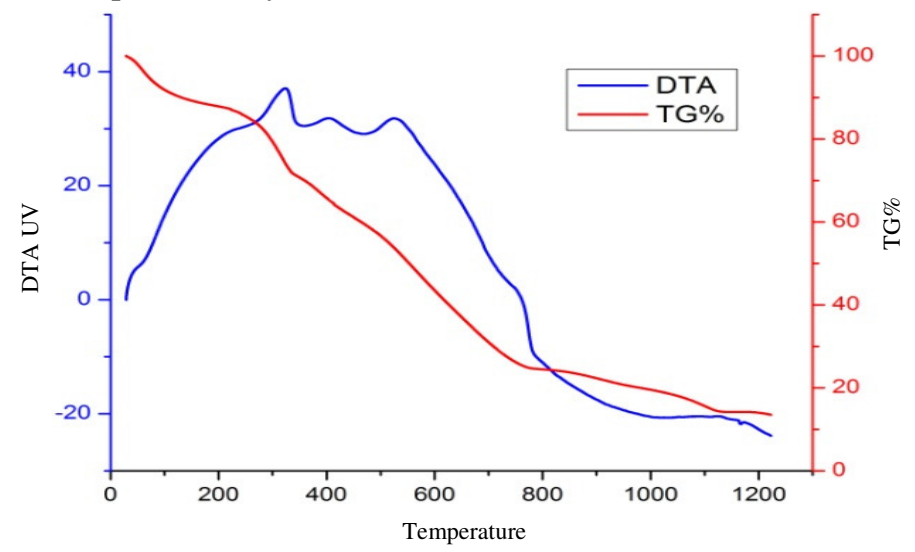

Figure 1. TG-DTA curves of $\mathrm{BaCe}_{0.7} \mathrm{Zr}_{0.3} \mathrm{O}_{3}$ powder preheated at $250{ }^{\circ} \mathrm{C}$ for $24 \mathrm{~h}$

From Figure 1 it can be seen that three regions were obtained in TG-DTA of the powder. The gradual weight loss is $12 \%$ up to $200{ }^{\circ} \mathrm{C}$ and is due to absorption of water molecules. The further weight loss along with exothermal peaks in DTA shows that the decomposition of gel takes place in two steps. The weight loss from 200 to $400{ }^{\circ} \mathrm{C}$ is found to be $23 \%$ accompanied with exothermic peak at $359{ }^{\circ} \mathrm{C}$ is due to combustion of the metal nitrates. The weight loss from $500-600{ }^{\circ} \mathrm{C}$ is $28 \%$ and the exothermic peak at $580{ }^{\circ} \mathrm{C}$ is due to co-oxidation. A very small weight loss is observed above $900{ }^{\circ} \mathrm{C}$ which is due to thermal decomposition of barium carbonate, also detected in XRD. TG curve displays a drastic weight loss starting at around $500{ }^{\circ} \mathrm{C}$ with a corresponding exothermic effect, which can be related to the decomposition of $\mathrm{BaCO}_{3}$ and the formation ${ }^{15,16}$ of $\mathrm{BaCe}_{0.7} \mathrm{Zr}_{0.3} \mathrm{O}_{3}$ with the release 
of $\mathrm{CO}_{2}$. This is consistent with the XRD results in Figure 2 that complete phase only forms upon heating at $1000{ }^{\circ} \mathrm{C}$ and above. There is no apparent weight change when the temperature is higher than $1100{ }^{\circ} \mathrm{C}$, indicating that the decomposition of $\mathrm{BaCO}_{3}$ and the formation of the compound have been completed. The total weight loss from $550{ }^{\circ} \mathrm{C}$ to $900{ }^{\circ} \mathrm{C}$ is around $30 \%$ calculated from TG result in Figure 1.

\section{$X$-ray diffraction $(X R D)$ analysis}

The phase compositions of $\mathrm{Zr}$ doped and pure $\mathrm{BaCeO}_{3}$ powders were identified by $\mathrm{x}$-ray diffraction (XRD) analysis. The experimental diffraction patterns were collected at room temperature by step scanning over the range $10^{\circ} \leq 2 \theta \leq 90^{\circ}$. As shown in Figure 2 calcined powders are predominantly the perovskite dominant structure, showing five major diffraction peaks, namely those from the (002), (022), (231), (611) and (422) planes (JCPDS card no. 22-0074). The XRD patterns of powders calcined at $1000^{\circ} \mathrm{C}$ for $12 \mathrm{~h}$ showed a single orthorhombic phase with Pnma space group. The lattice parameters were determined by least-square refinements and are listed in the Table 1.These parameters agree very well with earlier data for pure ${ }^{17-19} \mathrm{BaCeO}_{3}$. It was reported that phase formation in $\mathrm{BaCeO}_{3}$ obtained from solid state synthesis requires calcinations ${ }^{15,20-23}$ at $1100{ }^{\circ} \mathrm{C}$ or $1200{ }^{\circ} \mathrm{C}$ for $10 \mathrm{~h}$. Such high temperatures can lead to grain growth which causes decrease in surface area of the powder and consequent decrease in the sintered density. In the present study, $1000{ }^{\circ} \mathrm{C}$ was sufficient to produce a single phase material by adjusting the $\mathrm{pH}$ to 6 which liberates more protons from citric acid that helps to chelate $\mathrm{Ba}$ ions and enhance phase formation ${ }^{7}$. But, the small peak near $33^{0}$ may be due to $\mathrm{BaCO}_{3}$ which forms due to reaction of $\mathrm{BaCeO}_{3}$ with $\mathrm{CO}_{2}$.

Close examination of the XRD data reveals that as zirconium is incorporated replacing some $\mathrm{Ce}$ in the $\mathrm{B}$ sites the diffraction peaks shifted to higher angles and decrease of the lattice parameters is observed, which suggests a plane distance reduction (according to Bragg's law). This can be well explained by the fact that $\mathrm{Zr}^{4+}$ has a smaller ionic radius than $\mathrm{Ce}^{4+}$ and the appropriate doping and ordering of the atoms within the lattice reduces the strain. This results in the decrease in the cell volume which enhances structural stability against reactions with $\mathrm{CO}_{2}$, especially when the $\mathrm{Zr}$ content was above $\mathrm{x}=0.3$ which is reported in the literature. However substitution of zirconium has not altered the crystal structure. The crystallite sizes of the powder are calculated using Scherer's formula.

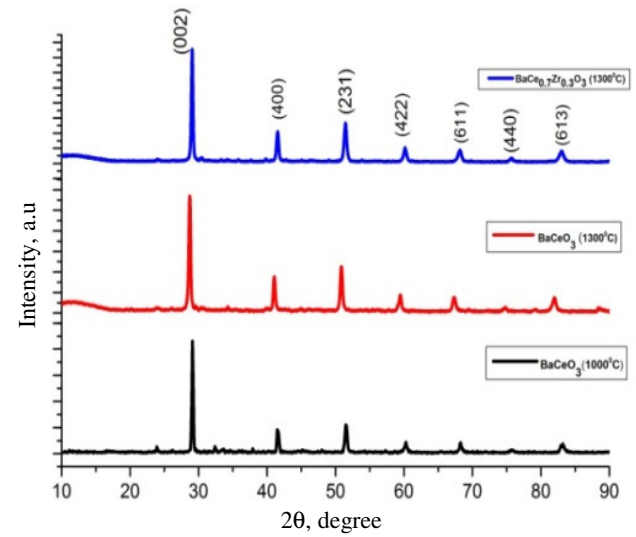

Figure 2a. XRD pattern of calcined (1000) and sintered powder $\left(1300^{\circ} \mathrm{C}\right)$ for $5 \mathrm{~h}$

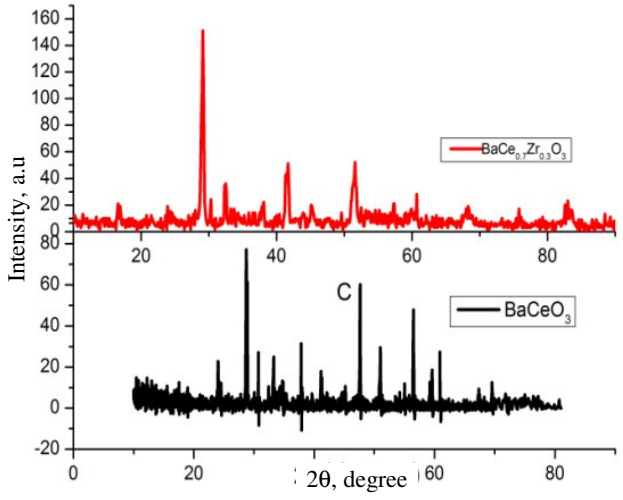

Figure 2b. XRD pattern after being exposed to boiling water 
Table 1. Unit cell Parameters of the sintered oxides at $1300{ }^{\circ} \mathrm{C}$ for 5 hours

\begin{tabular}{|c|c|c|c|}
\hline Different parameter & $\begin{array}{c}\text { Standard } \mathrm{BaCeO}_{3} \\
\text { (JCPDF no. 22-74) }\end{array}$ & $\mathrm{BaCeO}_{3}$ & $\mathrm{BaCe}_{0.7} \mathrm{Zr}_{0.3} \mathrm{O}_{3}$ \\
\hline Lattice parameters $(\AA)$ & $\mathrm{a}=8.779$ & $a=8.781$ & $a=8.570$ \\
\hline & $b=6.236$ & $\mathrm{~b}=6.210$ & $b=6.157$ \\
\hline & $c=6.214$ & $c=6.223$ & $c=6.348$ \\
\hline Cell volume $(\AA)^{3}$ & 340.19 & 339.376 & 334.9722 \\
\hline $\begin{array}{c}\text { Diffraction angle } 2 q \text { in } \\
\text { degree }\left(\begin{array}{lll}0 & 0 & 2\end{array}\right) \text { plane }\end{array}$ & 28.61 & 28.833 & 29.077 \\
\hline$\left(\begin{array}{lll}0 & 2 & 2\end{array}\right)$ & 40.968 & 41.125 & 41.566 \\
\hline$(231)$ & 50.898 & 50.8 & 51.659 \\
\hline$\left(\begin{array}{lll}4 & 2 & 2\end{array}\right)$ & 59.439 & 59.48 & 60.188 \\
\hline$\left(\begin{array}{lll}0 & 2 & 4\end{array}\right)$ & 67.422 & 67.447 & 68.06 \\
\hline$\left(\begin{array}{lll}4 & 4 & 0\end{array}\right)$ & 74.885 & 74.803 & 75.474 \\
\hline$\left(\begin{array}{lll}6 & 1 & 3\end{array}\right)$ & 82.004 & 81.919 & 82.9904 \\
\hline $\begin{array}{l}\text { Interplanar distance } \mathrm{d}(\AA) \\
\qquad\left(\begin{array}{lll}0 & 0 & 2\end{array}\right) \text { plane }\end{array}$ & 3.12 & 3.107 & 3.0672 \\
\hline$\left(\begin{array}{lll}0 & 2 & 2\end{array}\right)$ & 2.202 & 2.197 & 2.1742 \\
\hline$\left(\begin{array}{lll}2 & 3 & 1\end{array}\right)$ & 1.797 & 1.7935 & 1.7737 \\
\hline$\left(\begin{array}{lll}4 & 2 & 2\end{array}\right)$ & 1.555 & 1.553 & 1.53561 \\
\hline$\left(\begin{array}{lll}0 & 2 & 4\end{array}\right)$ & 1.389 & 1.3894 & 1.3757 \\
\hline$\left(\begin{array}{lll}4 & 4 & 0\end{array}\right)$ & 1.271 & 1.268 & 1.254 \\
\hline$\left(\begin{array}{lll}6 & 1 & 3\end{array}\right)$ & 1.174 & 1.18 & 1.162 \\
\hline Strain & & 0.0056 & 0.0048 \\
\hline
\end{tabular}

Where $D_{p}=$ Average crystallite size, $\beta=F W H M, \theta=$ Bragg angle, $\lambda=x$-ray wavelength. The crystallite size of the synthesized samples decreased from $29 \mathrm{~nm}$ to about $25 \mathrm{~nm}$ for $\mathrm{BaCe}_{0.7} \mathrm{Zr}_{0.3} \mathrm{O}_{3}$.

The bulk densities of the sintered pellets were determined using Archimedes displacement method. The densities of both the compounds are found to be $77 \%$ and $79 \%$ of the theoretical density for pure and doped samples respectively. In order to realise the effect of $\mathrm{Zr}$ doping on the structural stability, the distortion of cubic lattice was calculated based on the Goldsmith tolerance factor given by the formula;

$$
t=\frac{r_{A}+r_{o}}{\sqrt{2}\left(r_{\mathrm{B}}+r_{o}\right)}
$$

Where $t$ is the tolerence factor, $r_{A}$ is the ion radius of the A site where $\left.\mathrm{Ba}^{2+(} 1.35 \AA\right), r_{B}$ is the ionic radius of the $\mathrm{B}$ site $\left.\mathrm{Ce}^{4+} 0.87 \AA\right)$ and $\mathrm{Zr}^{4+}(0.72 \AA)$ and $\mathrm{r}_{\mathrm{O}}$ is the ionic radius of the oxygen.

A high value of $t$, close to unity increases the stability of the peroviskite phase and in the present composition incorporation of $\mathrm{Zr}$ increased the tolerance factor. Electro negativity also plays an important role in improving the stability ${ }^{19,24}$. High electro negativity of the dopant/ codopant reduces the interaction of the perovskite phase with acidic gases. $\mathrm{Zr}$ (1.33) exhibits higher electro negativity than $\mathrm{Ce}(1.12)$. These factors provide better stability to $\mathrm{BaCe}_{0.7} \mathrm{Zr}_{0.3} \mathrm{O}_{3}$ composition ${ }^{25}$. 


\section{Chemical stability}

In order to verify the stability under $\mathrm{H}_{2} \mathrm{O}$ containing atmospheres, the sintered pellets were boiled for $2 \mathrm{~h}$, dried and the XRD patterns were recorded. It has been observed that after exposed to boiling water, the undoped $\mathrm{BaCeO}_{3}$ pellets showed small $\mathrm{Ba}(\mathrm{OH})_{2}$ phases as shown in the Figure 2b. Due to reaction with $\mathrm{H}_{2} \mathrm{O} . \mathrm{BaCO}_{3}$ may also form due to interaction with atmospheric $\mathrm{CO}_{2}$ that converts $\mathrm{Ba}(\mathrm{OH})_{2}$ into carbonate. On the other these peaks are less intense in $\mathrm{BaCe}_{0.7} \mathrm{Zr}_{0.3} \mathrm{O}_{3}$ composition indicating its chemical stability in water.

A neutron diffraction study shows that, at room temperature and pressure, in the replacement of $\mathrm{Zr}$ with $\mathrm{Ce}$, the size of $\mathrm{BO}_{6}$ octahedral decreases with $\mathrm{x}$ at a much higher rate than the corresponding lattice parameters. Therefore the driving force for the evolution towards a symmetric structure is increased and it becomes more difficult to distort the perovskite structure. This also show that stability in water vapour increases with decreasing ionic radius of the codopant ${ }^{26,27}$.

\section{Microstructure}

The surface morphology of the sintered powders is shown in the Figure 3a, 3b. The average grain size is decreased from $1.33 \mu \mathrm{m}$ to $1.25 \mu \mathrm{m}$ for $\mathrm{BaCeO}_{3}$ and $\mathrm{BaCe}_{0.7} \mathrm{Zr}_{0.3} \mathrm{O}_{3}$ respectively. This is consistent with the fact that the grain size decreases as the ionic radius of the dopant decreases.

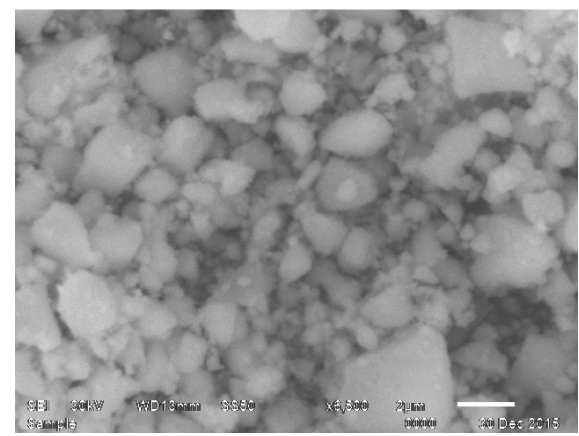

(a)

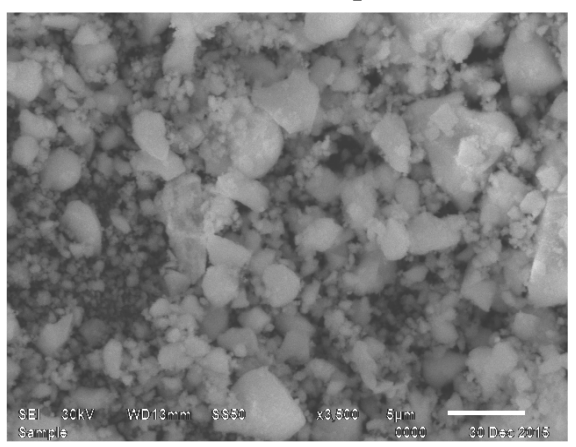

(b)

Figure 3. SEM morphologies of sintered $\left(1300{ }^{0} \mathrm{C} / 5 \mathrm{~h}\right)$ powders $(3 \mathrm{a}) \mathrm{BaCeO}_{3}$ and $(3 \mathrm{~b})$ $\mathrm{BaCe}_{0.7} \mathrm{Zr}_{0.3} \mathrm{O}_{3}$

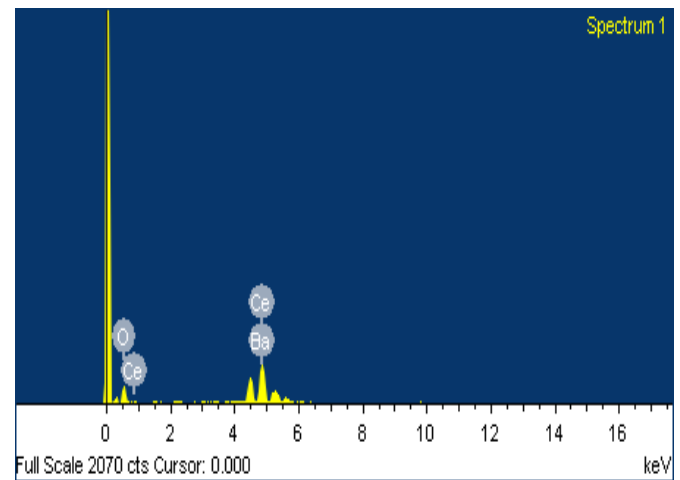

(a)

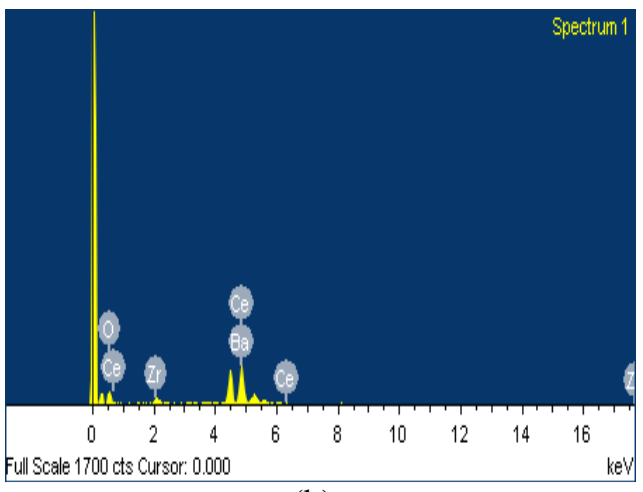

(b)

Figure 4. EDAX Analysis of sintered $\left(1300{ }^{0} \mathrm{C} / 5 \mathrm{~h}\right)$ powders (4a) $\mathrm{BaCeO}_{3}$ and (4b) $\mathrm{BaCe}_{0.7} \mathrm{Zr}_{0.3} \mathrm{O}_{3}$ 
The sintered powders were nalysed by energy-dispersive x-ray spectroscopy (EDX) for elemental analysis. The spectra Figure $4 \mathrm{a}, 4 \mathrm{~b}$ Show that only Barium, Zirconium and Cerium elements are present and that they are found in stoichiometric proportion. In addition, no impurities were found.

\section{Fourier transforms infrared (FTIR) spectroscopy}

FTIR analysis was used to explain in further detail the formation of this carbonate species during heat treatment. FT-IR spectrum of the precursor of the sintered powders is shown in Figure 5. The presence of a sharp peak at $857 \mathrm{~cm}^{-1}$ may be due to the $=\mathrm{C}-\mathrm{H}$ bend and the bands at 1080, 1182 and $1130 \mathrm{~cm}^{-1}$ were also assigned to the carbonate peaks (C-O stretch) due to carboxylic group present in the powder burnt to $\mathrm{CO}_{2}$ during heating and some of the $\mathrm{CO}_{2}$ molecules are absorbed on the powders. In order to produce the single phase ceramic powders, the decomposition process of the gel should be controlled to suppress the formation of carbonates of constituent species, since those carbonates give possible segregation and in homogeneity in the final oxide powders. The peak localised in the range of $1450-1470 \mathrm{~cm}^{-1}$ attributed to the $\mathrm{C}-\mathrm{H}$ bend and which may be due to the complex formed from a chelating process of chelating agents and metal ions ${ }^{12-17,20}$.

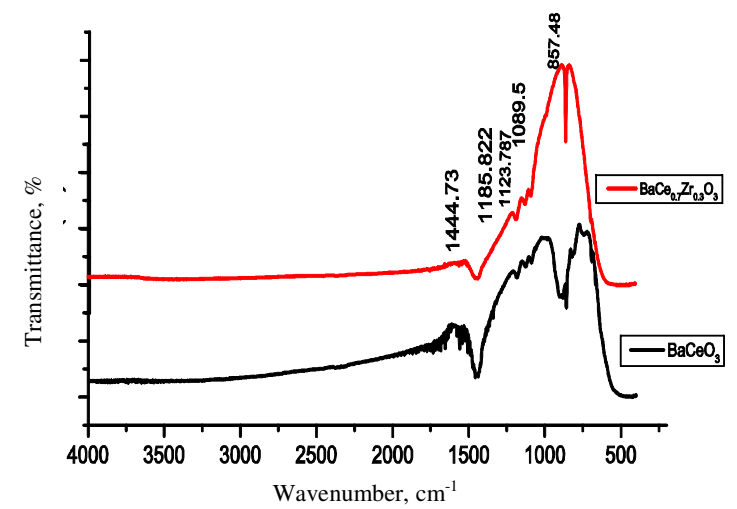

Figure 5. FTIR spectra of sintered $\left(1300{ }^{0} \mathrm{C} / 5 \mathrm{~h}\right)$ powders

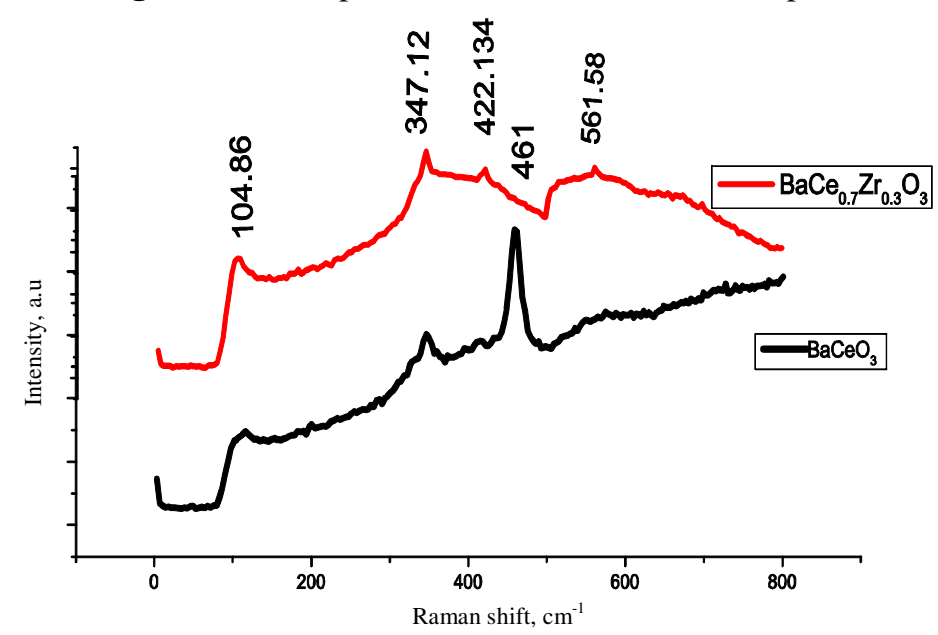

Figure 6. Raman spectra of sintered $\left(1300^{\circ} \mathrm{C} / 5 \mathrm{~h}\right)$ powders 


\section{Fourier transforms Raman spectroscopy}

Raman spectra recorded for $\mathrm{BaCeO}_{3}$ and $\mathrm{BaCe}_{0.7} \mathrm{Zr}_{0.3} \mathrm{O}_{3}$ at room temperature are shown in the Figure 6. The XRD analysis gives only the long range structural characteristics, while Raman spectroscopy sensitive to structural symmetry, can detect any possible short range structural variation $(20-100 \AA)^{28}$. The bands at $80-150 \mathrm{~cm}^{-1}$ were assigned to the O-Ce-O bending and the peaks in the wave number range $300-350 \mathrm{~cm}^{-1}$ corresponds to the perovskite phase. In the case of $\mathrm{Zr}$ doping there is a gradual shift in the peak from $344.9 \mathrm{~cm}^{-1}$ in pure $\mathrm{BaCeO}_{3}$ to $347.12 \mathrm{~cm}^{-1}$ in $\mathrm{BaCe}_{0.7} \mathrm{Zr}_{0.3} \mathrm{O}_{3}$ samples. Atomic mass of $\mathrm{Zr}$ is less than $\mathrm{Ce}$, hence the average mass of $\mathrm{B}$ sites in $\left[\mathrm{Ce}[\mathrm{Zr}] \mathrm{O}_{6}\right]$ octahedral decreases on the substitution, resulting in the shift to a higher frequency. This is consistent with the fact that vibrational frequency is inversely proportional to the square root of reduced mass and the weak peak may be due to bending mode of $\mathrm{ZrO}_{6}$. A small peak near $461 \mathrm{~cm}^{-1}$ was attributed to characteristic signal of the $\mathrm{Ce}-\mathrm{O}$ bond $^{24}$ and are consistent with the data available in the literature ${ }^{29-31}$. The small peak $560 \mathrm{~cm}^{-1}$ in $\mathrm{Zr}$ doped $\mathrm{BaCeO}_{3}$ may be assigned to the stretching mode of $\mathrm{ZrO}_{6}$ which is absent in pure sample.

\section{Impedance analysis}

The impedance spectra measured in air from $200{ }^{\circ} \mathrm{C}$ to $400{ }^{\circ} \mathrm{C}$ for pure and $\mathrm{Zr}$ doped $\mathrm{BaCeO}_{3}$ are shown in the Figure $7 \mathrm{a}, 7 \mathrm{~b}$. Generally the spectra consisted of three arcs at high, medium and low frequencies, corresponding to the response of bulk, grain boundary and the electrode respectively ${ }^{32,33}$ in the Nyquist plots $\left(Z^{\prime} v s . Z^{\prime \prime}\right)$. In the present work, the high frequency semi circle related to bulk response could not be seen due to the instrumental limitations of the experimental range in the Nyquist plots. Therefore, the bulk response was assigned to the high frequency intercept of the medium arc with the real axis. The Arrhenius plots were obtained from the conductivity data using the Arrhenius equation given by

$$
\sigma_{\mathrm{ac}}=\sigma_{\mathrm{o}} \exp \left(\frac{-\mathrm{E}_{\mathrm{a}}}{\mathrm{K}_{\mathrm{b}} \mathrm{T}}\right)
$$

Where, $\sigma_{\mathrm{o}}, \mathrm{Ea}, \mathrm{k}_{\mathrm{b}}, \mathrm{T}$ are pre-exponential factor, activation energy, Boltzmann constant and absolute temperature, respectively.

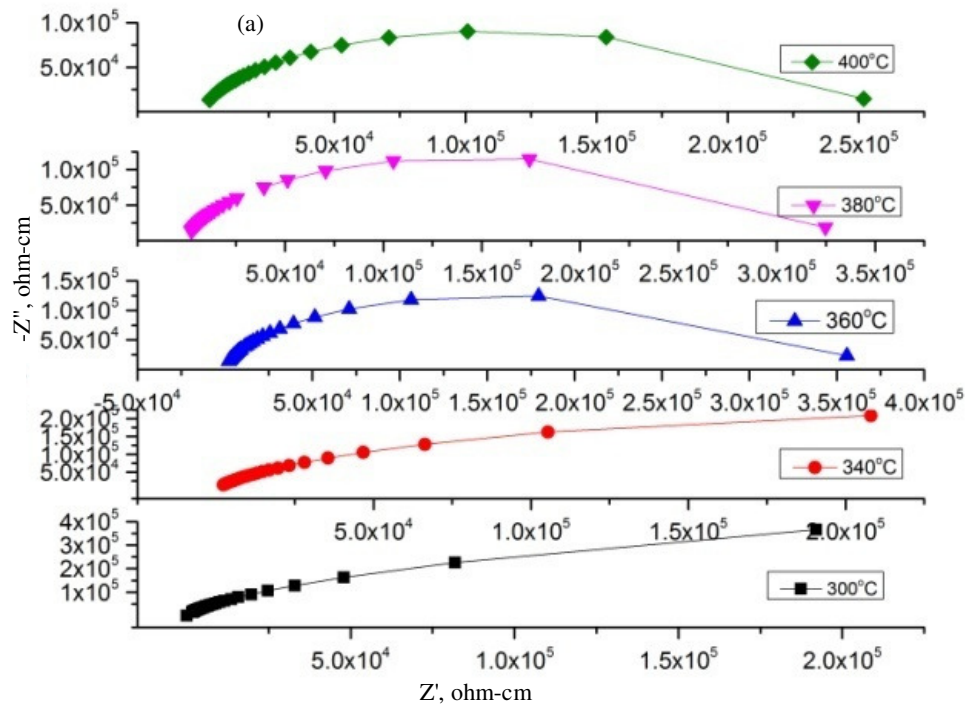




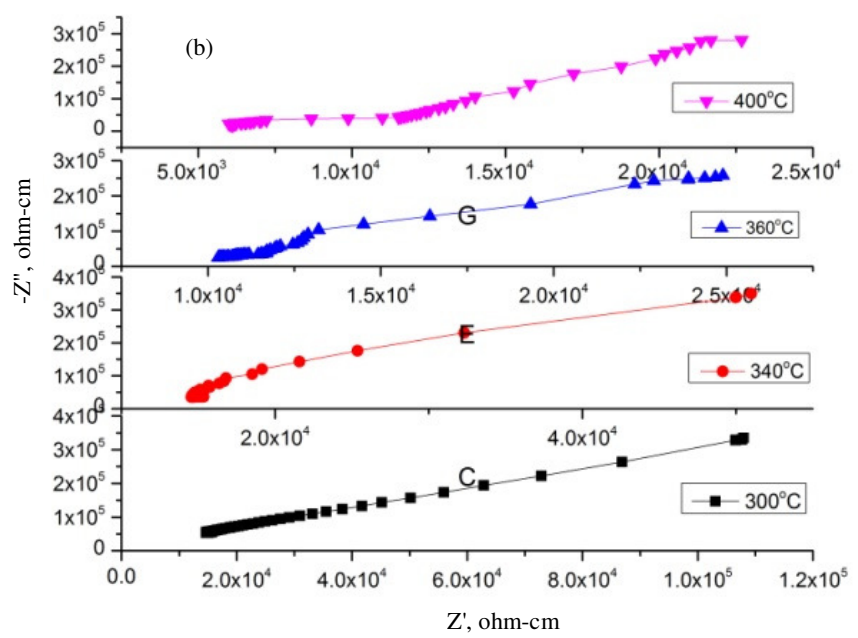

Figure 7. Nyquist plots of samples measured from different temperatures in air atmosphere (7a) $\mathrm{BaCeO}_{3}$ and (7b) $\mathrm{BaCe}_{0.7} \mathrm{Zr}_{0.3} \mathrm{O}_{3}$

In air atmosphere, the Arrhenius plot of both the samples followed a linear trend from 200 to $400{ }^{\circ} \mathrm{C}$ as shown in the Figure 8 . Oxygen ions are conducted with the assistance of oxygen vacancies present in the lattice. The conductivity in air does not show any signature of proton conduction as no water is present to create the protonic charge carriers. Hence, the conductivity is low and activation energy is higher than a proton conducting mechanism ${ }^{34}$. The conductivity values of $\mathrm{BaCeO}_{3}$ and $\mathrm{BaCe}_{0.7} \mathrm{Zr}_{0.3} \mathrm{O}_{3}$ are found to be $1.92 \times 10^{-6} \mathrm{~S} / \mathrm{cm}$ and $1.35 \times 10^{-6} \mathrm{~S} / \mathrm{cm}$ respectively. The conductivity increases as temperature increases and the activation energies determined from the slope of the plot Log $\sigma$ vs. 1000/T are $1.18 \mathrm{eV}$ and $1.25 \mathrm{eV}$ respectively ${ }^{35,36}$. These values are in agreement with that available in the literature $\sigma=2.4910^{-7} \mathrm{~S} . \mathrm{m}^{-1}$ at $\mathrm{T}=150^{\circ} \mathrm{C}$ to $\sigma=1.5510^{-3} \mathrm{~S} . \mathrm{m}^{-1}(0.94 \mathrm{eV})$ at $\mathrm{T}=950{ }^{\circ} \mathrm{C}$ using acetates ${ }^{32}$ and $3 \times 10^{-7}$ at $600{ }^{\circ} \mathrm{C}$ using solid state reaction method $^{8}$.

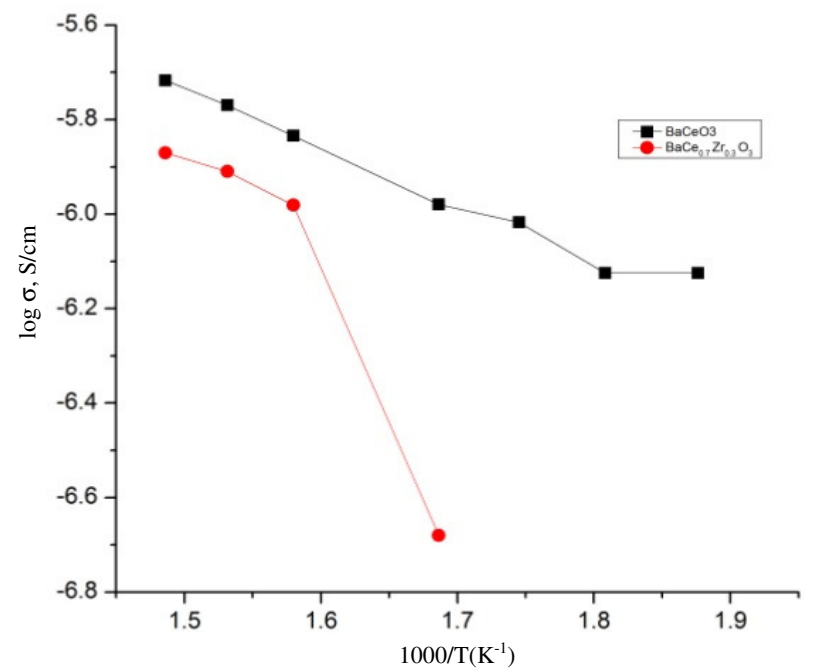

Figure 8. Arrhenius plot of conductivity in air for samples sintered at $1300{ }^{\circ} \mathrm{C} / 5 \mathrm{~h}$ 
A slight decrease in the conductivity is observed when $\mathrm{Zr}$ is doped which can be explained from the fact that the decrease in the average grain size eventually increases the grain boundary resistance which resulted in the decrease in the conductivity ${ }^{36,37}$. However the decrease can be compensated with the increase in the chemical stability of the sample which is essential to meet the requirements of fuel cell applications. Comparisons of grain conductivity and activation energies with other works are presented in Table 2.

Table 2. Calculated values of sintered oxides at $1300{ }^{\circ} \mathrm{C}$ for 5 hours with reported values

\begin{tabular}{lccc}
\hline \multirow{2}{*}{ Different parameter } & \multirow{2}{*}{$\mathrm{BaCeO}_{3}[\mathrm{Ref}]$} & $\mathrm{BaCeO}_{3}$ & $\mathrm{BaCe}_{0.7} \mathrm{Zr}_{0.3} \mathrm{O}_{3}$ \\
\cline { 3 - 4 } & & $($ This work $)$ & $(\mathrm{This} \mathrm{work})$ \\
\hline Crystallite Size, $\mathrm{nm}$ & & 25.72 & 25.6 \\
Average grain size, $\mu \mathrm{m}$ & $1-4 \mu \mathrm{m}[34]$ & 1.3446 & 1.253 \\
Relative Density & & $77 \%$ & $79 \%$ \\
Tolerance factor & 0.856 & 0.856 & 0.874 \\
Conductivity, $\mathrm{S} / \mathrm{cm}$ & $3 \times 10^{-7}\left(600^{\circ} \mathrm{C}\right)[32]$ & $1.92 \times 10^{-6}\left(400^{\circ} \mathrm{C}\right)$ & $1.35 \times 10^{-6}\left(400^{\circ} \mathrm{C}\right)$ \\
Activation energy $(\mathrm{eV})$ & $1.17 \pm 0.03[34]$ & 1.18 & 1.25 \\
\hline
\end{tabular}

The variation of dielectric constant with temperature $\left(200^{\circ}-400{ }^{\circ} \mathrm{C}\right)$ and frequency (20 Hz to $1 \mathrm{MHz}$ ) were studied. From the frequency dependent plot Figure 9a, 9b. It was observed that the value of $\varepsilon_{\mathrm{r}}$ decreases sharply as the frequency increases. The higher values of dielectric constant at low frequencies can be due to space charge polarisation (power frequencies) which occurs due to pile up of charges at the interfaces between the sample and the electrode. This can be explained on the behaviour of the dipole movement as follows. Dielectric behaviour of samples with frequency is related to the applied electric field. An alternating electric field changes its direction with time. With each direction reversal, the polarisation components are required to follow the field reversal. So the polarisation depends on the ability of dipoles to orient themselves in the direction of the field during each alternative change of the field. At low frequency regions the diploes will get sufficient time to orient themselves completely along the field direction, resulting in larger values of $\varepsilon_{\mathrm{r}}$ of the samples. As the frequency increases further, the dipoles in the samples cannot reorient themselves fast enough to respond to the applied electric field, resulting in the decrease in $\varepsilon_{\mathrm{r}}$ of the samples up to $10^{6} \mathrm{~Hz}$.

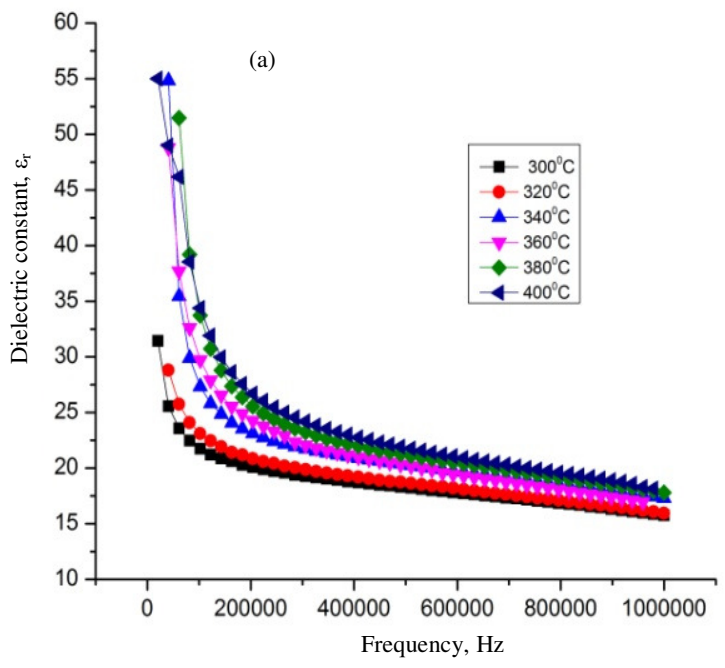




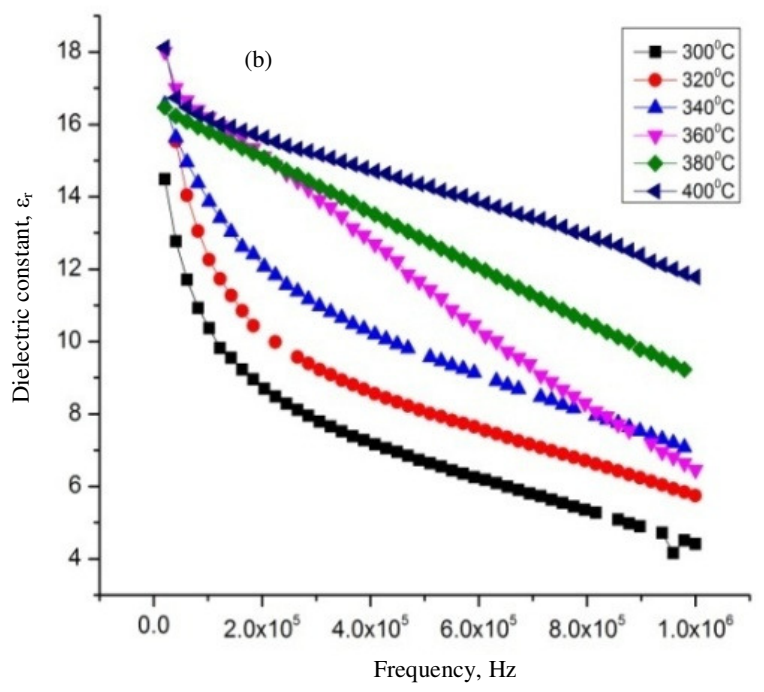

Figure 9. Dielectric constant vs. frequency plot of sintered $\left(1300{ }^{\circ} \mathrm{C} / 5 \mathrm{~h}\right)$ powders (9a) $\mathrm{BaCeO}_{3}$, (9b) $\mathrm{BaCe}_{0.7} \mathrm{Zr}_{0.3} \mathrm{O}_{3}$

From the plot of dielectric constant versus temperature (Figure 10) it was observed that as temperature increased the dielectric constant also increased. This can be explained as follows. In space charge polarisation, the increase in temperature facilitates the diffusion of ions. Thermal energy may also aid in overcoming the activation barrier for the orientation of polar molecules in the direction of the field which increases the value of $\varepsilon$.

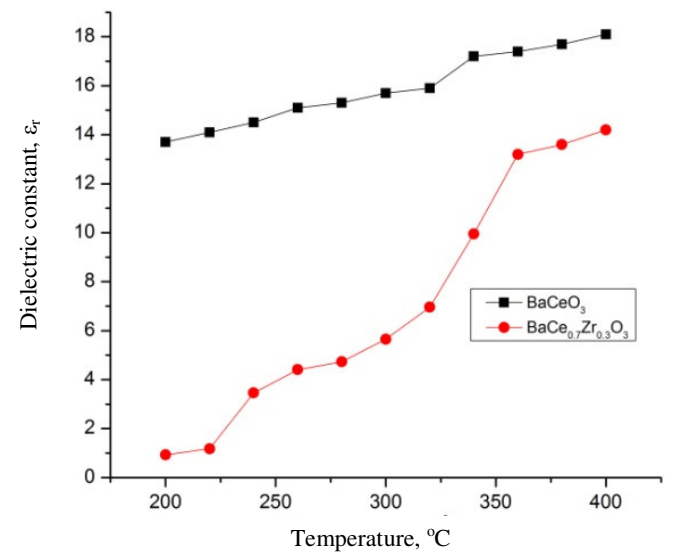

Figure 10. Variation osf dielectric constant with temperature of sintered, $\left(1300{ }^{\circ} \mathrm{C} / 5 \mathrm{~h}\right)$ powders

\section{Conclusion}

Pure and $\mathrm{Zr}$ doped $\mathrm{BaCeO}_{3}$ were synthesized at low temperature via a sol-gel method using nitrates of barium, cerium and zirconium as precursors. This method avoids the use of carbonates of barium presenting the disadvantage of leaving residues of carbonates disappearing only at very high temperature as in the case of solid state reaction method. In addition, this method had the advantage to reduce temperature of heat treatment and therefore 
to minimize crystallite size of the final compound. Both of x-ray diffraction and SEM confirm the presence of a single phase of $\mathrm{BaCeO}_{3}$. The TGA/ DTA data revealed the removal of moisture and other organics from the precursor materials. Also, the TGA/ DTA data helped to find out the suitable calcination temperature to prepare phase-pure compound. The powder XRD data obtained with pure and $\mathrm{Zr}$ doped $\mathrm{BaCeO}_{3}$ powder is in good agreement with the standard reported JCPDS data. The crystal structure of $\mathrm{BaCeO}_{3}$ is orthorhombic with Pnma space group. The EDAX data confirmed the presence of required elements in both samples. From the FTIR and Raman spectra data, it is understood that the characteristic peak of $\mathrm{Ce}-\mathrm{O}$ is present in both samples. The conductivity values of $\mathrm{BaCeO}_{3}$ and $\mathrm{BaCe}_{0.7} \mathrm{Zr}_{0.3} \mathrm{O}_{3}$ are found to be $1.92 \times 10^{-6} \mathrm{Scm}^{-1}$ and $1.35 \times 10^{-6} \mathrm{Scm}^{-1}$ respectively. The decrease in the conductivity can be compensated with the increase in the chemical stability of $\mathrm{BaCe}_{0.7} \mathrm{Zr}_{0.3} \mathrm{O}_{3}$ sample which is essential to meet the requirements of fuel cell applications and hence this composition with some doped trivalent ions can be used as a promising electrolyte in fuel cell applications.

\section{Acknowledgement}

The authors wish to thank the Coordinator DST-Purse Programme, Advanced Analytical laboratory, Andhra University for providing XRD, SEM, FTIR and LCR measurements used in this work.

\section{References}

1. Chu S and Majumdhar A, Nature, 2012, 488(7411), 294-303; DOI:10.1038/nature11475

2. Sorrel S and Irvine J T S, Nat Mater., 2003, 2, 320-323; DOI:10.1038/nmat871

3. Tao S, Speirs J, Bentle R, Miller R and Thompson E, Energy, 2012, 37(1), 709-724; DOI:10.1016/j.energy.2011.10.010

4. Daniele P, et al. Nature Materials, 2003, 9(2), 846-852; DOI:10.1021/n18036728

5. Amini M M and Mirzaee M, Ceram Int., 2009, 35(6), 2367-2372; DOI:10.1016/j.ceramint.2009.01.009

6. Boschini F, Rulmont A, Cloots R, Vertruyen B, J Eur Ceram Soc., 2009, 29(8), 1457 1462; DOI:10.1016/j.jeurceramsoc.2008.09.001

7. Knight K S and Bonanos N, Mater Res Bull., 1995, 30(3), 347-356.

8. Chem Q, Braun A, Yoon S, Bagdassarav N and Graule J, J Eur Ceram Soc., 2011, 31, 2657-2661; DOI:10.1016/j.jeurceramsoc.2011.02.014

9. Ushiba K, Chem Tech., 1984, 300.

10. Katahira K, Kohchi Y, Shimura T and Iwahara H, Solid State Ionics., 2000, 138(1-2), 91-98; DOI:10.1016/S0167-2738(00)00777-3

11. Kinoshita K and Cairns E J, Encyclopedia Chem Technol., 1994, 11, 1098

12. MoteKaites R J, Cox X B, Taylor P, Martell A E, Miles B and Tvedt T J, J Chem., 1982, 60(10), 1207-1213; DOI:10.1139/v82-179

13. Galceran M, Pujol M C, Aguilo M and Diaz F, J Sol Gel Sci Technol., 2007, 42(1), 79-88; DOI:10.1007/s10971-006-1517-3

14. Hodgson N B and Shen X, J Mater Sci., 2000, 35(21), 5275-5282; DOI:10.1023/A:1004826324526

15. Deganello F, Marci G, Deganello G, J Eur Ceram Soc., 2009, 29(3), 439450;.DOI:10.1016/j.jeurceramsoc.2008.06.012

16. Chien R R, Tu C S, Hugo-Schmidt V, Lee S C and Huang C C, Solid State Ionics. 2010, 181(27-28), 1251-1257; DOI:10.1016/j.ssi.2010.07.024

17. Tu, C S, Chein R R, Schimdt V H, Lee S C, Haung C C and Tsai C L, J Appl Phys., 2009, 105(10), 103504-103507; DOI:10.1063/1.3117835 
18. Mai H X, Sun L D, Zhang Y W, Si R, Feng W, Zhang H P, Liu H C and Yan C H, $J$ Phys Chem., 2005, 8(51), 109, 24380-24385; DOI:10.1021/jp055584b

19. Dalal P V and Saraf K B, Bull Mater Sci., 2006, 29, 421-425; DOI:10.1007/BF02914071

20. Babilo $\mathrm{P}$ and Haile S M, J Am Ceram Soc., 2005, 88(9), 2362-2368; DOI:10.1111/j.1551-2916.2005.00449.x

21. Ding $\mathrm{H}$ and Xue X, J Power Sources, 2010, 195(20), 7038-7041; DOI:10.1016/j.jpowsour.2010.05.010

22. Inorganics Grating Spectra M I. Sadtler Research Laboratories Inc. Vol s.l-2, pp. Y1K-Y600K, 1965.

23. Pfaff G, Hildebrand V D and Fuess H, J Mater Sci Lett., 1998, 17(23), 1983-1985; DOI:10.1023/A:1006652405086

24. Knight K S, Solid State Ionics, 2001, 145(1-4), 275-294; DOI:10.1016/S01672738(01)00952-3

25. Kreuer K D, Апnu Rev Mater Res, 2003, 33, 333-359; DOI:10.1146/annurev.matsci.33.022802.091825

26. Pannier T and Charrier I C, Ritter C and Lucazeau G, J Eur Phys J AP, 2000, 9(1), 1-9; DOI:10.1051/epjap:2000192

27. Kim J H, Kang Y M, Myoung S B and Kwang T H, Thin Solid Films, 2011, 520(3), 1015-1021; DOI:10.1016/j.tsf.2011.08.013

28. Knight K S, Solid State Ionics, 1994, 74(3-4), 109-117; DOI:10.1016/01672738(94)90199-6

29. Yushan Hou, Jianfang Wu and Elena Yu Konysheva, Int J Hdrogen Energy Elsvier, 2016, 41(6), 3994-4004; DOI:10.1016/j.ijhydene.2015.12.168

30. Chaudhuri M K and Das B, Inorg Chem., 1986, 25(2), 168-170; DOI:10.1021/ic00222a015

31. Tu C S, Haung C C, Lee S C, Chien R R, Schmid V H and Tsai C L, Solid State Ionics, 2010, 181(37-38), 1654-1658; DOI:10.1016/j.ssi.2010.09.052

32. Ouzaouit K C S, Benlhachemi A, Benyaich H, Dallas J P, Villain S, Musso J A, Gavarri J R, Condensed Mater, 2006, 7(1).

33. Babu A S and Ranjit Bauri, Int J Hydrogen Energy, 2014, 39(26), 14487-14495, DOI:10.1016/j.ijhydene.2014.03.249.

34. Agnieszka Lacz, Katarzyna Grzesik and Pawel Pasierb, J Power Sources, 2015, 279, 80-87; DOI:10.1016/j.jpowsour.2014.12.065

35. Jia-Huan Xu, Jun Xiang, Hui Ding, Tang-Qi Yu, Jia-Le Li, Zhao-Guang Li, Yue-Wen Yang and Xi-Le Shao, $J$ Alloys Compounds, 2013, 551(1-2), 333-337; DOI:10.1016/S0925-8388(02)00032-4

36. Park H J, Kwak Ch, Lee K H, Lee S M and Lee E S, J Eur Ceram Soc., 2009, 29(12), 2429-2437; DOI:10.1016/j.jeurceramsoc.2009.02.010

37. Jin-Ho Kim, Yong-Mook Kang, Myoung-Seob Byun and Kwang-Taek Hwang, Thin Solid Films, 2011, 520(3), 1015-1021; DOI:10.1016/j.tsf.2011.08.013 